\title{
Preparation and Properties of Waterborne $\mathrm{PUA} / \mathrm{SiO}_{2} / \mathrm{TiO}_{2}$ Composite Materials
}

\author{
Xiaoying Zhang, Fengxian Qiu* \\ School of Chemistry and Chemical Engineering \\ Jiangsu University \\ Zhenjiang, China \\ e-mail:fxqiuchem@163.com
}

\begin{abstract}
A series of waterborne poly(urethaneacrylate)/silica/titania (WPUA/SiO $/ \mathrm{TiO}_{2}$ ) composite materials were prepared by the sol-gel technique. The physical, mechanical and thermal properties of $\mathrm{WPUA} / \mathrm{SiO}_{2} / \mathrm{TiO}_{2}$ dispersions and films were measured. The prepared composite materials were characterized by the means of FT-IR spectra, scanning electron microscope (SEM), transmission electron microscope (TEM), Differential scanning calorimetry (DSC) and X-ray diffraction (XRD) measuring apparatus to get their structures, surface morphologies, thermal properties, etc. The results showed that $\mathrm{SiO}_{2}-\mathrm{TiO}_{2}$ composite particles of the films had uniform dispersion, forming an excellent interfacial bonding layer on their surface. The prepared composite materials showed good thermal stability and mechanical properties in comparison with pure WPUA. When $\mathrm{SiO}_{2}: \mathrm{TiO}_{2}$ was 8:2, hybrid material had the best mechanical properties.
\end{abstract}

Keywords-waterborne poly(urethane-acrylate); silica; titania; mechanical property

\section{INTRODUCTION}

Recently, the organic-inorganic composites can be formed by reacting an inorganic alkoxide directly with an organic polymer or an oligomer having the appropriate functional groups, which providing covalent linkages between the organic phase and the inorganic network $[1,2]$. Waterborne polyurethane-acrylate (WPUA) is probably the most versatile polymer material, with a wide variety of physical and chemical properties. $\mathrm{TiO}_{2}$, which is the most common compound of titanium, is often used in many applications ranging from anticorrosion, self-cleaning coatings, and paints to solar cells and photocatalysts $[3,4]$. Silica $\left(\mathrm{SiO}_{2}\right)$ is another commonly used inorganic particle due to its low price and chemical stability, as well as other factors. In order to improve the compatibility between the organic and inorganic phases, it is essential to establish chemical linkages between the soft organic and the hard inorganic phases.

In this work, a series of WPUA/SiO$/ \mathrm{TiO}_{2}$ composite materials were prepared by the sol-gel technique. The prepared composite materials were characterized using UVVis, FT-IR, XRD, SEM, TEM and DSC methods. Some properties of the WPUA/ $\mathrm{SiO}_{2} / \mathrm{TiO}_{2}$ composite materials were determined.

\section{EXPERIMENTAL}

Preparation of waterborne poly(urethane-acrylate) (WPUA) dispersion: A certain amounts of polyether polyol (NJ-210) and isophorone diisocyanate (IPDI) were added into a four-necked flask. Then, dibutylbis (lauroyloxy)tin (DBLT) was added as catalyst and the mixture was heated to $80-85^{\circ} \mathrm{C}$ and keeping the temperature for $2 \mathrm{~h}$. Next, a certain amounts of dimethylpropionic acid (DMPA) and hydroxyethyl methyl acrylate (HEMA) were added into the system and reacted at $60{ }^{\circ} \mathrm{C}$ for $5 \mathrm{~h}$. When the temperature was cooled down to $40{ }^{\circ} \mathrm{C}$, triethylamine (TEA) were added into the flask subsequently and reacted at $40{ }^{\circ} \mathrm{C}$ for $30 \mathrm{~min}$. After neutralization, a mixture of calculated butyl acrylate (BA) and methyl methacrylate (MMA) were added and was then dispersed into deionized water under vigorous stirring. Azobisisobutyronitrile (AIBN) was added into the dispersion subsequently at $40^{\circ} \mathrm{C}$. After being reacted for $4 \mathrm{~h}$, the WPUA dispersion was obtained.

Preparation of $\mathrm{SiO}_{2}$ and $\mathrm{TiO}_{2}$ sols: The hydrolyzed tetraethoxysilane (TEOS) sol was prepared with deionized water, hydrochloric acid, ethanol, and TEOS in a conical flask, and was stirred for $1 \mathrm{~h}$. And the hydrolyzed TBT sol was prepared the same way.

Preparation of $\mathrm{WPUA} / \mathrm{SiO}_{2} / \mathrm{TiO}_{2}$ material dispersion: WPUA/ $/ \mathrm{SiO}_{2} / \mathrm{TiO}_{2}$ dispersion was prepared via sol-gel process. The homogeneous organic solution was obtained from coupling agent 3-glycidyloxypropyl trimethoxysilane (GLYMO) and WPUA at $40^{\circ} \mathrm{C}$ for $1 \mathrm{~h}$. Then, the homogeneous inorganic solution was added carefully to the organic solution and reacted for another $1 \mathrm{~h}$, which was the mixture of prepared $\mathrm{SiO}_{2}$ and $\mathrm{TiO}_{2}$ sols. Then, the temperature was cooled to room temperature and kept stirring for $12 \mathrm{~h}$. Varied the ratio of $\mathrm{SiO}_{2}: \mathrm{TiO}_{2}$, a series of WPUA $/ \mathrm{SiO}_{2} / \mathrm{TiO}_{2}$ dispersions were obtained with different $\mathrm{SiO}_{2}: \mathrm{TiO}_{2}$ of 5:5, 7:3, 8:2 and 9:1 (named as Hyb-1, Hyb -2, Hyb-3 and Hyb-4, respectively).

Films preparation: Films were prepared by casting the WPUA or hybrid dispersions into a poly(tetrafluoroethylene) mold, laying aside at room temperature for $1-2$ days and then at $60^{\circ} \mathrm{C}$ for $3 \mathrm{~h}$.

Measurements and characterization: The apparent viscosity was measured by a numerical viscometer (NDJ-9S, Shanghai Precision \& Scientific Instrument Co., Ltd, China). The particle diameters were measured by the laser particle size analyzer (BIC-9010, Brookhaven Instrument Co., USA). 
Tensile strength test and elongation at break for all specimens were carried out on a tensile tester (KY-8000A, Jiangdu Kaiyuan Test Machine Co., Ltd, China). FT-IR spectra were obtained on a $\mathrm{KBr}$ powder (AVATAR 360, Nicolet, USA). UV-Vis spectra were recorded using UV-Vis spectrometer (UV2450, shimadzu, Japan). Scanning electron microscope (SEM) were investigated with $20 \mathrm{kV}$ accelerating voltage (S-4800, HITACHI Corporation, Tokyo, Japan). Transmission electron microscopy (TEM) was observed using an acceleration voltage of $120 \mathrm{kV}$ (TECNAI-12, Philips Company, Eindhoven, Netherlands). X-ray diffraction (XRD) patterns were recorded by the reflection scan with nickel-filtered $\mathrm{Cu} \mathrm{K} \alpha$ radiation (D8, Bruker-AXS, Karlsruhe, Germany). Differential scanning calorimetry (DSC) was performed on a Netzsch instrument (204F1, NETZSCH, Germany).

\section{Results And Discussion}

\section{A. The properties of dispersions}

The storage stability, viscosity, surface tension, and particle size are shown in Table I. It could be seen that all the dispersions showed acceptable storage stability and had little apparent change in viscosity. The particle size of hybrid emulsion was significantly bigger than the pure WPU and WPUA emulsions.

TABle I. Some Physical Properties of Dispersions

\begin{tabular}{|c|c|c|c|c|c|c|}
\hline \multirow{2}{*}{ Samples } & \multicolumn{6}{|c|}{ Table Column Head } \\
\hline & WPU & WPUA & Hyb -1 & $H y b-2$ & Hyb -3 & $H y b-4$ \\
\hline Appearance & $\#, \$$ & $\#, \$$ & $\begin{array}{l}\#, \\
*\end{array}$ & $\begin{array}{l}\#, \\
*\end{array}$ & $\begin{array}{l}\#, \\
*\end{array}$ & $\#, *$ \\
\hline $\begin{array}{l}\text { Storage stability } \\
(>12 \text { months })\end{array}$ & $\star$ & $\star$ & $\star$ & $\star$ & $\star$ & $\star$ \\
\hline $\begin{array}{c}\text { Viscosity } \\
(\mathrm{Pa} \cdot \mathrm{s})\end{array}$ & 1.843 & 1.320 & 1.332 & 1.299 & 1.359 & 1.286 \\
\hline $\begin{array}{l}\text { Particle Size } \\
(\mathrm{nm})\end{array}$ & 99.6 & 125.6 & 138.2 & 206.7 & 175.5 & 142.6 \\
\hline
\end{tabular}

\section{B. Mechanical properties of WPUA and materials}

Figure 1 shows the curves of tensile strength and elongation at break for pure WPUA and WPUA/ $/ \mathrm{SiO}_{2} / \mathrm{TiO}_{2}$ materials. Their tensile strength was different with the ratio of $\mathrm{SiO}_{2}: \mathrm{TiO}_{2}$.

From Figure 1, all WPUA/ $\mathrm{SiO}_{2} / \mathrm{TiO}_{2}$ materials have higher tensile strength than the pure WPUA. The curve of the tensile strength exhibits a single peak, which increases from the ratio of $\mathrm{SiO}_{2}: \mathrm{TiO}_{2}$ of 0 to $9: 1$, while $\mathrm{SiO}_{2}: \mathrm{TiO}_{2}=8: 2$, it reaches the maximum $10.86 \mathrm{MPa}$, shows outstanding mechanical properties. Moreover, it was interesting that the curve of elongation-at-break shows the same trend like the tensile strength. It increases initially with ratio of $\mathrm{SiO}_{2}: \mathrm{TiO}_{2}$, and then decreases when $\mathrm{SiO}_{2}: \mathrm{TiO}_{2}$ is $>8: 2$.

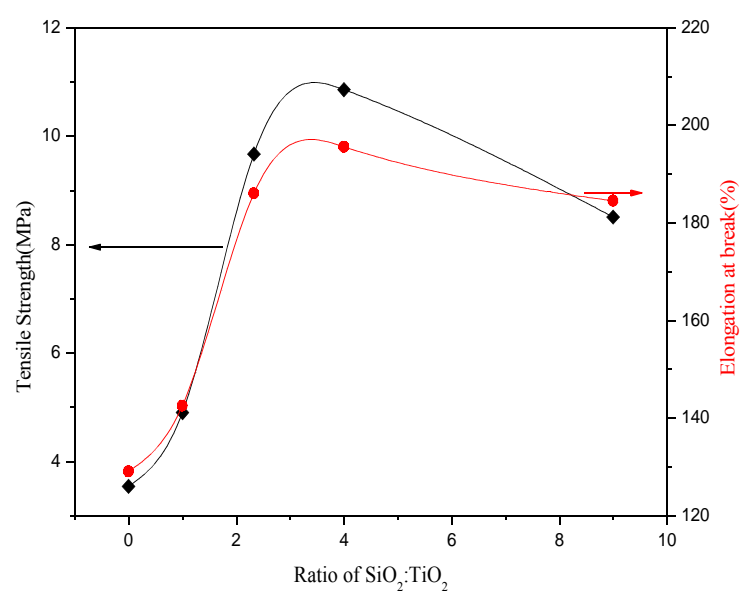

Figure 1. Tensile strength and elongation at break of WPUA and WPUA $/ \mathrm{SiO}_{2} / \mathrm{TiO}_{2}$ materials

\section{UV-Vis spectra}

Figure 2 shows the transmittance of WPU, WPUA and WPUA/ $\mathrm{SiO}_{2} / \mathrm{TiO}_{2}$ materials in the wavelength range of 350$800 \mathrm{~nm}$.

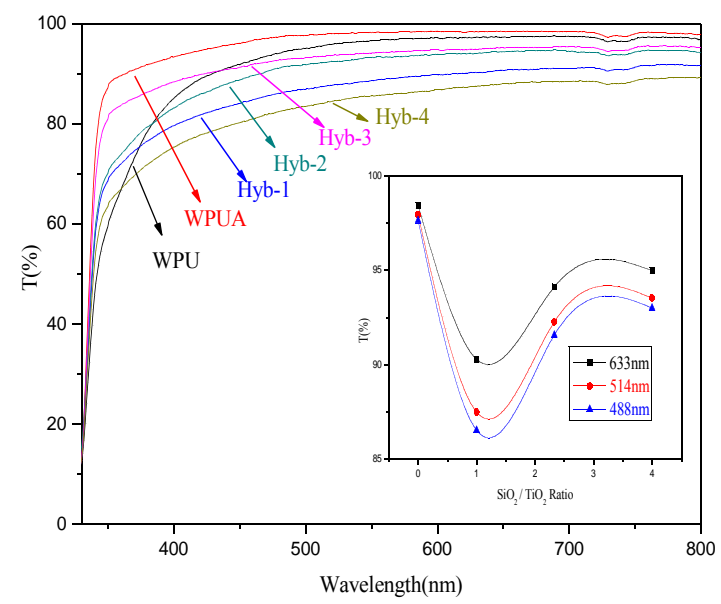

Figure 2. Transmittance variation of the samples

As shown in the inset, the transmittance at $633 \mathrm{~nm}$ decreases from $98.8 \%$ of pure WPUA to $90.5 \%$ of the hybrid with $\mathrm{SiO}_{2}: \mathrm{TiO}_{2}=5: 5$, and then gradually increases from 90.5 to $94 \%$ of the hybrid with $\mathrm{SiO}_{2}: \mathrm{TiO}_{2}=7: 3$, and then reaches $95 \%$ with $\mathrm{SiO}_{2}: \mathrm{TiO}_{2}=8: 2$. The transmittance of material also shows the same trend at the $514 \mathrm{~nm}$ and $488 \mathrm{~nm}$. It is because the smaller refractive index of pure silica and titania than the WPUA. Thus, the refractive index can be decreased with adding the mixture of $\mathrm{SiO}_{2}$ and $\mathrm{TiO}_{2}$. However, transmittance rises with the increasing of ratio $\mathrm{SiO}_{2}: \mathrm{TiO}_{2}$, this is because the silica and titania particles are blended into WPUA to form an aggregation phase in the hybrid matrix. This leads to an increase in the transparence of the hybrid 
film. These results suggest that the transparence of the prepared hybrid thin film could be tunable through the adjustment of $\mathrm{SiO}_{2}$ and $\mathrm{TiO}_{2}$ ratio.

\section{FT-IR spectra}

FT-IR spectra of WPUA, Hyb-1, Hyb-2 and Hyb-3 were obtained. In FT-IR spectra, there is a strong absorption peak at about $1730 \mathrm{~cm}^{-1}$ for each sample, corresponding to the carbamate carbonyl $(-\mathrm{C}=\mathrm{O})$ stretching vibration peak, which can prove the prepared products is polyurethane with urethane bond. The characteristic absorption of the $\mathrm{C}=\mathrm{C}$ bond at $1640 \mathrm{~cm}^{-1}$, disappears, indicating that the acrylic monomers have been polymerized. There are wide and strong absorption peak from 1050 to $1150 \mathrm{~cm}^{-1}$ in WPUA and WPUA $/ \mathrm{SiO}_{2} / \mathrm{TiO}_{2}$ materials, show the existence of a Si$\mathrm{O}-\mathrm{Si}$ backbone, which due to the polycondensation between the siloxane side the of coupling agent GLYMO and the hydrolysis of TEOS, forming Si-O-Si network, generating the interpenetrating polymer network between the organic and inorganic phase. There is an absorption peak at about $930 \mathrm{~cm}^{-1}$ corresponding to the characteristic absorption of Si$\mathrm{O}-\mathrm{Ti}$ bond in the WPUA/ $/ \mathrm{SiO}_{2} / \mathrm{TiO}_{2}$ materials, and the absorption peak at about $544 \mathrm{~cm}^{-1}$ is the stretching vibration absorption for $\mathrm{Ti}-\mathrm{O}-\mathrm{Ti}$. In addition, it can be observed that there is strong Ti-O bond absorption at $490 \mathrm{~cm}^{-1}$, corresponding to $\mathrm{C}-\mathrm{O}-\mathrm{Ti}$ bond absorption at $1260 \mathrm{~cm}^{-1}$, indicating that the combination of $\mathrm{TiO}_{2}$ and polymer is carried out by the Ti-O-C bond.

\section{E. X-ray diffraction}

The XRD is the most powerful technique for monitoring the formation and structure of intercalated. Figure 3 shows the X-ray diffraction curves for WPUA, Hyb-1, Hyb-2 and Hyb-3.

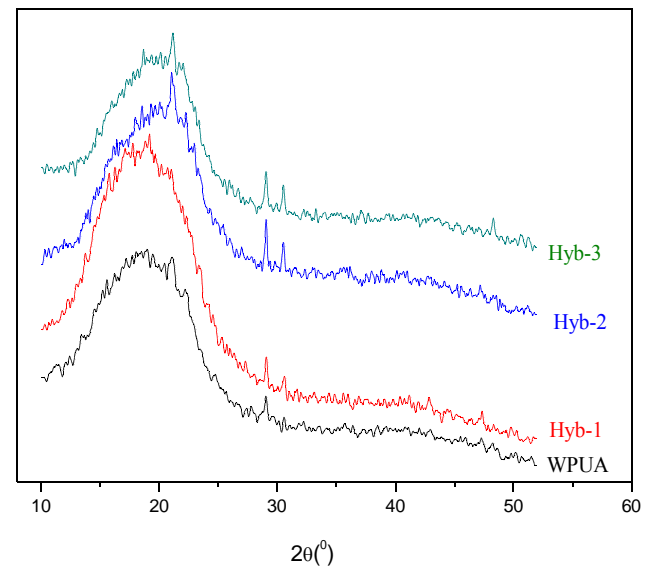

Figure 3. XRD of samples

For pure WPUA and hybrid materials, nearly amorphous diffraction peak is seen near $2 \theta=20^{\circ}$, indicating the crystalline of polyester segments. In addition, some sharp diffraction peak appeared at $2 \theta=29^{\circ}, 30.5^{\circ}$ for WPUA and all hybrid materials, their intensities increased with the increasing ratio of $\mathrm{SiO}_{2}: \mathrm{TiO}_{2}$, and those peak was attributed to the short-range-order arrangement of chain segments of amorphous polyurethane and the formation of uniform threedimensional network structure, which interspersed with WPUA segment. The X-ray diffraction of Hyb-2, Hyb-3 are similar, when $\mathrm{SiO}_{2}$ : $\mathrm{TiO}_{2} \geq 7: 3$, two sharp diffraction peak appeared at $2 \theta=18^{\circ}$ and $21.1^{\circ}$, it maybe corresponding to the diffraction peak of $\mathrm{SiO}_{2}$.

\section{F. SEM Characterization}

The cross-sections of WPUA and Hyb-3 material were observed by SEM morphology in Figure 4. Obviously, the surface of Hyb-3 show more regular, dense structure after the modification by $\mathrm{SiO}_{2}-\mathrm{TiO}_{2}$ composite particles, which is due to the chemical bond was formed between $\mathrm{SiO}_{2}-\mathrm{TiO}_{2}$ composite, WPUA and TBT in the presence of GLYMO, and then engender the cross-network, improving the compatibility between organic and inorganic phase. Moreover, owe to GLYMO, the "bridge" role make the network more compact. This surface morphology has provided further proof for the good performance of the hybrid material.

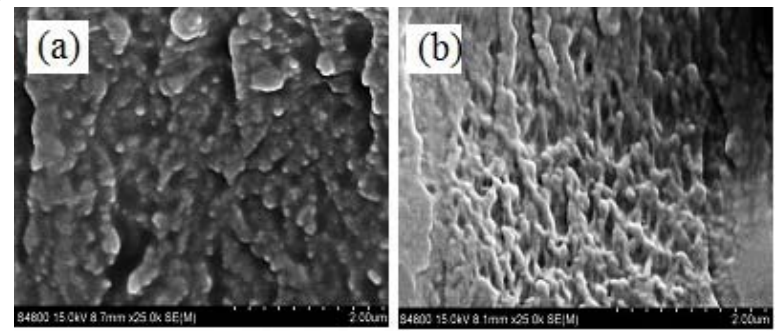

Figure 4

SEM photographs of (a) WPUA, and (b) Hyb-3

\section{G. TEM Characterization}

As shown in Figure 5, a considerable number of circular nano-scaled particles dispersed uniformly in WPUA matrix was observed, which is mainly due to nano- $\mathrm{SiO}_{2}$ has been effectively restricted to the regular molecular network structure of poly(urethane-acrylate).
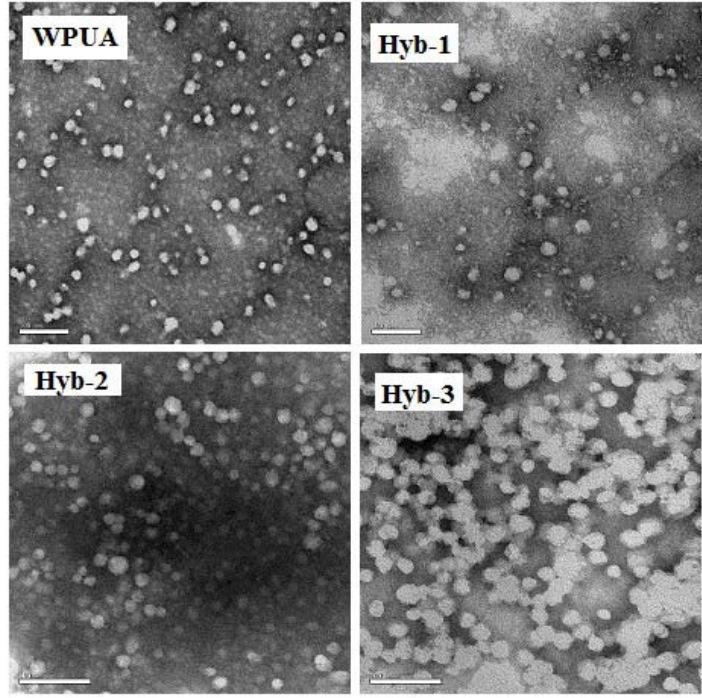
Figure 5. TEM photographs of (a) WPUA, (b) Hyb-1, (c) Hyb-2,(d) Hyb3

On the other hand, that is, covalent bonding ( $\mathrm{Si}-\mathrm{O}-\mathrm{Si}$ and Ti-O-Ti) between the organic and inorganic components enhanced miscibility. They were homogeneously and uniformly dispersed at a molecular level. The formation silica-titania particles in the as-prepared WPUA and coupling agent GLYMO matrix indicated that the $-\mathrm{Si}\left(\mathrm{OCH}_{3}\right)_{3}$ and $-\mathrm{Ti}\left(\mathrm{OCH}_{3}\right)_{3}$ groups may be functioned as internal "bridging" groups between organic and inorganic segments for sol-gel reactions of TEOS and TBT molecules. With the ratio of $\mathrm{SiO}_{2}: \mathrm{TiO}_{2}$ increases, the particle size also increase. Also, it was not observed agglomerate or large accumulation phenomenon between the $\mathrm{SiO}_{2}-\mathrm{TiO}_{2}$ composite particles. It is mainly due to the WPUA chain in solution inhibits the particle growth which cause growing particle can't form bigger particle, meanwhile, the $\mathrm{SiO}_{2}$ film coated nano- $\mathrm{TiO}_{2}$ particles, reducing the surface energy of nano$\mathrm{TiO}_{2}$, inhibiting the aggregation of $\mathrm{TiO}_{2}$ particles.

\section{H. DSC Measurement}

Figure 6 showed the DSC scan curves for WPUA and WPUA/ $/ \mathrm{SiO}_{2}$ films.

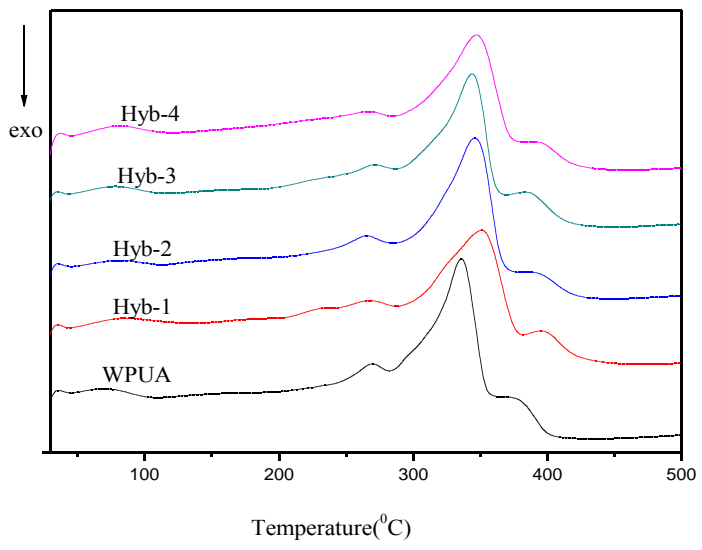

Figure 6. DSC curves of WPUA and WPUA/ $\mathrm{SiO}_{2} / \mathrm{TiO}_{2}$ films

(1) The $\mathrm{WPU} / \mathrm{SiO}_{2}$ films had higher glass transition temperature $\left(T_{\mathrm{g}}\right)$ of hard segment than WPU film; (2) There was only a glass transition temperature in the all film samples. The result indicated that polymers were almost completely compatible, the phenomenon was because of the copolymerization between organic polymer WPUA and inorganic $\mathrm{SiO}_{2}-\mathrm{TiO}_{2}$ components occurred, greatly improving the compatibility, close to the molecular level mixed; (3) The all films had higher decomposition temperatures $\left(T_{\mathrm{d}}>335^{\circ} \mathrm{C}\right)$; (4) The decomposition temperature of the composite material $\left(T_{\mathrm{d}} \approx 350{ }^{\circ} \mathrm{C}\right)$ was significantly higher than WPUA, indicating that the thermal stability of hybrid materials were improved; (5) The decomposition temperature of WPUA $/ \mathrm{SiO}_{2} / \mathrm{TiO}_{2}$ film samples increased with the increasing of $\mathrm{SiO}_{2}: \mathrm{TiO}_{2}$ ratio.

\section{CONCLUSIONS}

A series of WPUA/ $/ \mathrm{SiO}_{2} / \mathrm{TiO}_{2}$ composite materials were prepared by sol-gel process. Compare with WPUA aqueous dispersion, the particle size of the hybrid aqueous dispersion increased from $125.6 \mathrm{~nm}$ to $206.7 \mathrm{~nm}$. PA and $\mathrm{SiO}_{2}-\mathrm{TiO}_{2}$ components modification enhanced toughening effect, greatly improved mechanical properties; this was due to chemical network formations between the organic and inorganic phases. Composite materials had pretty good transparency and high thermal stability; and TEM results showed that the hybrid particles have core-shell structure in nano-scale, indicating that good compatibility of organic and inorganic phase. From the integrated performance, $\mathrm{SiO}_{2}: \mathrm{TiO}_{2}$ is $8: 2$ is the suitable ratio, Hyb-3 shows the best performance.

\section{ACKNOWLEDGMENT}

This project was supported by the Innovation Program for Graduate Education of Jiangsu Province (SJLX_0477) and Society Development Fund of Zhenjiang (SH2014074 and SH2013020).

\section{REFERENCES}

[1] D.M. Wu, F.X. Qiu, H.P. Xu, J.L. Zhang and D.Y. Yang, "Preparation, characterization, and properties of environmentally friendly waterborne poly(urethane acrylate)/silica hybrids," Journal of Applied Polymer Science, vol. 119, Feb. 2011, pp. 1683-1695, DOI: 10.1002/app.32846.

[2] D.M. Wu, F.X. Qiu, H.P. Xu and D.Y. Yang, "Waterborne polyurethane/inorganic hybrid composites: preparation, morphology and properties," Plastics, Rubber and Composites, vol. 40, Nov. 2011 , pp. 449-456, DOI 10.1179/1743289810Y.0000000045.

[3] W.C. Liaw and K.P. Chen, "Preparation and characterization of poly(imide siloxane) (PIS)/titania(TiO2) hybrid nanocomposites by sol-gel processes," European Polymer Journal, vol. 43, Jun. 2007, pp 2265-2278, DOI: 10.1016/j.eurpolymj.2007.01.015.

[4] V. Amita, M. Kar and S.A. Agnihotry, "Aging effect of diethanolamine stabilized sol on different properties of $\mathrm{TiO} 2$ films: electrochromic applications," Solar Energy Materials and Solar Cells, vol. 91, Sep. 2007, pp. 1305-1312, DOI: 10.1016/j.solmat.2007.04.028. 